\title{
Conduta cirúrgica do derrame pleural parapneumônico em adultos
}

\author{
Surgical treatment for parapneumonic pleural \\ effusion in adults
}

\section{Daniel Reis Waisberg', Francini Mambrini Pires Rego', Renato Tavares Bellato', Lucas de Oliveira Hortêncio ${ }^{1}$, Jader Joel Machado Junqueira ${ }^{2}$, Ricardo Mingarini Terra ${ }^{3}$, Fabio Biscegli Jatene ${ }^{4}$}

\begin{abstract}
Waisberg DR, Rego FMP, Bellato RT, Hortêncio LO, Junqueira JJM, Terra RM, Jatene FB. Conduta cirúrgica do derrame pleural parapneumônico em adultos/Surgical treatment for parapneumonic pleural effusion in adults. Rev Med (São Paulo). 2011 jan.-mar.;90(1):15-28.

RESUMO: Cerca de $40 \%$ dos pacientes portadores de pneumonia desenvolverão derrame pleural parapneumônico (DPP), o que está associado a considerável morbimortalidade. O DPP possui três fases: exsudativa, fibrino-purelenta e de organização, que representam o progresso da doença. Apesar das várias opções de tratamento existentes, a conduta terapêutica não está bem estabelecida, visto que para cada fase a eficácia de cada método é variável. Procurou-se, nesta revisão de literatura, analisar as diversas opções disponíveis e os critérios que determinam sua indicação. De modo geral, o uso da toracocentese terapêutica deve ser restrito a casos de DPP simples pequenos, que ocupam até metade do hemitórax. Já a toracostomia com drenagem fechada apresenta indicação mais ampla: DPP simples volumosos ou DPP complicados e empiema livres na cavidade. Para tais casos com múltiplas loculações, a decorticação vídeo-assistida (VATS) constitui o tratamento ideal. Por fim, a decorticação por toracotomia está indicada em casos mais crônicos com encarceramento pulmonar, embora existam evidências de que a VATS também pode ser empregada nesses casos e, em caso de necessidade, convertida no intra-operatório para toracotomia. Em relação aos agentes fibrinolíticos, os dados existentes sobre sua eficácia são contraditórios, de modo que seu uso ainda é restrito.

ABSTRACT: At least, $40 \%$ of all patients with pneumonia will have a parapneumonic pleural effusion (PPE), which is associated to considerable morbidity and mortality. The PPE has three phases: exsudative, fibrinopurulent and organizing, which represent the development of the disease. Despite the great number of therapeutic methods, the PPE management is not well established, because for each phase the success rate of each technique is variable. The objective of this review of literature was to analyze each method available and its indications. Briefly, the use of therapeutic thoracocentesis is restricted to small simple PPE, which are limited to half of the hemithorax. On the other hand, tube thoracostomy has a wider indication: large simple effusions and free-flowing complicated PPE or empyema. For multiloculated cases, the Video-assisted Thoracoscopic Surgery (VATS) is recommendable. Finally, the decortication through thoracotomy is indicated for chronic cases with lung entrapment, although there are evidences that VATS can be used too and, if needed, converted to thoracotomy in the operation room. Regarding thrombolytics, the data available about its efficacy is controversial, thereby its use is still very restricted.
\end{abstract}

DESCRITORES: Derrame pleural/cirurgia; Pneumonia; Cirurgia torácica; Literatura de revisão como assunto.
KEYWORDS: Pleural effusion/surgery; Pneumonia; Thoracic surgery; Review literature as topic.

Trabalho premiado no COMU 2010 - Prêmio Monografia.

1. Acadêmico do Curso de Medicina da Faculdade de Medicina da Universidade de São Paulo (FMUSP).

2. Residente em Cirurgia Torácica do Hospital das Clínicas da Faculdade de Medicina da Universidade de São Paulo (FMUSP).

3. Médico Assistente do Serviço de Cirurgia Torácica do Hospital das Clínicas da Faculdade de Medicina da Universidade de São Paulo (HCFMUSP).

4. Professor Titular da Disciplina de Cirurgia Torácica da Faculdade de Medicina da Universidade de São Paulo (FMUSP).

Endereço para correspondência: Laboratório Anátomo-Cirúrgico do Instituto do Coração (InCor) - HCFMUSP. Rua Dr. Enéas de Carvalho

Aguiar, 44 - 2º Andar / Bloco 1 - Cerqueira César. CEP: 05403-900 - São Paulo/SP. E-mail: daniel_waisberg@ hotmail.com 


\section{INTRODUÇÃO}

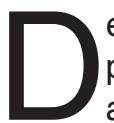
efine-se o derrame pleural parapneumônico (DPP) como o acúmulo anormal de líquido na cavidade pleural secundário a pneumonia ou abscesso pulmonar de etiologia bacteriana (excetuando-se Mycobacterium tuberculosis, que configura um derrame tuberculoso) ${ }^{1}$.Por definição, o empiema pleural ocorre quando da presença de pus no espaço pleural, originalmente estéril. Procedimentos diagnósticos sobre o espaço pleural, cirurgia torácica prévia, extensão de abscesso subfrênico, ruptura de esôfago, entre outros, também podem ser causas de derrame pleural associados a infeccção². Contudo, a etiologia parapneumônica é a mais freqüente, correspondendo a cerca de 50\% dos casos $^{3}$. Trata-se de uma patologia altamente prevalente, visto que aproximadamente $20 \%$ de todos os pacientes portadores de pneumonia desenvolverão um $\mathrm{DPP}^{3,4}$, resultando em cerca de 1 milhão de acometidos anualmente nos EUA, com uma taxa geral de mortalidade de $15 \%$ (5), que se acentua nos extremos de vida, chegando a $75 \% \mathrm{em}$ maiores de 70 anos e $28 \%$ nos menores de 12 anos 3,5 . Ademais, cerca de 40 a $60 \%$ das pneumonias mais acentuadas e que cursam com internação hospitalar também apresentarão DPP, contribuindo para que sua presença influencie a mortalidade de pacientes com pneumonia, elevando-a cerca de 6,5 vezes em derrames bilaterais e 3,5 vezes em unilaterais ${ }^{6,7}$.

Não obstante a ampliação dos métodos terapêuticos disponíveis nas últimas décadas ${ }^{8}$, a conduta para o tratamento do DPP ainda é controversa $^{2-5}$. Desta forma, o objetivo deste estudo foi revisar as diversas opções descritas na literatura para o tratamento do DPP em adultos, propondo um modelo de conduta baseado em evidências.

\section{Fisiopatogenia}

O completo processo de desenvolvimento do derrame pleural parapneumônico perdura de 5 a 6 semanas $^{1}$ e desenvolve-se segundo três fases clínicas que constituem um espectro contínuo $0^{1,3,5}$. A primeira, denominada fase exsudativa ou DPP simples, é caracterizada pelo acúmulo de líquido estéril no espaço pleural devido ao aumento do fluxo proveniente do parênquima pulmonar e da permeabilidade capilar elevada nas pleuras visceral e parietal. Sua duração compreende de 1 a 2 semanas após o início do quadro pneumônico. A segunda fase, denominada fibrino-purulenta ou DPP complicado, ocorre em resposta à invasão bacteriana via extravasamento capilar e tecido danificado, podendo perdurar por de 1 a 6 semanas após o início do quadro. Em razão da lesão inflamatória, o equilíbrio fibrótico do espaço pleural é alterado, havendo a formação de coágulos de fibrina e septos fibrosos, que geram a loculação desse espaço. Por fim, na terceira fase ou de organização, ocorre deposição de tecido fibroso na superfície interior das membranas pleurais, levando ao típico espessamento pleural. Isto gera o encarceramento pulmonar, uma vez que a expansão do pulmão torna-se prejudicada, acarretando redução de hematose e potencial infecção crônica. Esta fase inicia-se geralmente após 5 ou 6 semanas após a instalação da pneumonia.

\section{Quadro clínico}

Em virtude da presença de sintomas como tosse, febre, dor torácica e dispnéia, as fases do DPP não são clinicamente distinguíveis entre si, tampouco o são pacientes com DPP ou apenas processo pneumônico ${ }^{5,7,9}$.

A tríade mais freqüentemente observada nos pacientes sintomáticos em decorrência da presença de um derrame pleural é: dor torácica, tosse seca e dispnéia. O espectro de apresentações clínicas é amplo, variando desde pacientes completamente assintomáticos até pacientes em franco choque séptico, dependendo principalmente do microorganismo causador e da resposta imune gerada. O tratamento precoce para pacientes com suspeita de infecção pulmonar muitas vezes mascara o aparecimento de sintomas. Considerase crônico o DPP presente de 4 a 6 semanas, o que eleva o risco de complicações, tais como: empiema necessitans (drenagem espontânea pela parede ou para o parênquima pulmonar), condrite e osteomielite costal, fístula broncopleural, pericardite, abscesso mediastinal e sepse $e^{1,9}$.

\section{Diagnóstico laboratorial}

Para o correto tratamento do DPP, fazse necessária a identificação precisa do estado fisiopatológico do processo, uma vez que isto influencia diretamente na seleção das opções terapêuticas. Pela impossibilidade de diferenciação clínica de cada etapa, a análise bioquímica do líquido pleural constitui o método mais adequado para tal fim. Light et al. ${ }^{10} \mathrm{e}$ Potts et al. ${ }^{11}$ demonstraram que o $\mathrm{pH}$, a concentração de glicose e DHL são extremamente úteis para a determinação de tais fases (Tabela 1). A visualização macroscópica de pus no líquido pleural já delimita a fase de empiema. Todos os DPP são caracterizados pelo predomínio de neutrófilos. Caso células mononucleadas sejam majoritárias, um diagnóstico alternativo deve ser feito. 
TABELA 1. Características bioquímicas, citológicas e microbiológicas do fluído pleural em cada fase do DPP ${ }^{12}$

\begin{tabular}{|c|c|c|c|}
\hline Características & $\begin{array}{l}\text { Derrame parapneumônico } \\
\text { simples }\end{array}$ & $\begin{array}{c}\text { Derrame parapneumônico } \\
\text { complicado }\end{array}$ & Empiema \\
\hline Aparência & Clara ou levemente turva & Turva & Pus \\
\hline $\begin{array}{l}\text { Marcadores } \\
\text { bioquímicos } \\
\text { (Critérios de Light) }\end{array}$ & $\begin{array}{l}\mathrm{pH}>7.30 \\
\mathrm{DHL} \text { aumentada menos que três } \\
\text { vezes o limite superior sérico } \\
\text { Glicose }>60 \mathrm{mg} / \mathrm{dL}\end{array}$ & $\begin{array}{l}\mathrm{pH}<7.20 \\
\mathrm{DHL}>1000 \mathrm{IU} / \mathrm{L} \text { ou mais que três } \\
\text { vezes o limite superior sérico } \\
\text { Glicose }<35 \mathrm{mg} / \mathrm{dL}\end{array}$ & não se aplica \\
\hline $\begin{array}{l}\text { Contagem de células } \\
\text { nucleadas }\end{array}$ & Neutrófilos $<10000$ celúlas/ $\mu \mathrm{L}$ & Neutrófilos $>10000$ células/ $\mu \mathrm{L}$ & não se aplica \\
\hline $\begin{array}{l}\text { Coloração de Gram e } \\
\text { cultura }\end{array}$ & Negativa & Possivelmente positiva & Possivelmente positiva \\
\hline
\end{tabular}

Com base nas características apresentadas na Tabela 1 e na presença de loculações, Light procurou subdividir os DDP em diversas categorias para sugerir intervenções específicas em cada uma delas ${ }^{13}$. Contudo, Heffner et al. ${ }^{14}$ elaboraram uma meta-análise que mostrou que o $\mathrm{pH}$ era o marcador bioquímico mais sensível, que primeiro se altera na passagem de fase I para fase II. Esse achado incentivou a produção de outra meta-análise ${ }^{15}$, que resultou na classificação do American College of Chest Physicians (ACCP) (resumida na Tabela 2). Por meio das características anatômicas, bioquímicas e bacteriológicas do líquido pleural os pacientes com DPP são categorizados com base nos fatores prognósticos, semelhante à escala TNM (do inglês, tumor-node-metastasis).

TABELA 2. Risco categorizado para prognóstico desfavorável nos portadores de DPP ${ }^{15}$

\begin{tabular}{|c|c|c|c|c|c|c|c|}
\hline $\begin{array}{l}\text { Anatomia do espaço } \\
\text { pleural }\end{array}$ & & $\begin{array}{l}\text { Bacteriologia do } \\
\text { líquido pleural }\end{array}$ & & $\begin{array}{l}\text { Bioquímica do } \\
\text { líquido pleural }\end{array}$ & Categoria & $\begin{array}{c}\text { Risco de } \\
\text { prognóstico } \\
\text { desfavorável }\end{array}$ & $\begin{array}{l}\text { Necessidade } \\
\text { de drenagem }\end{array}$ \\
\hline $\begin{array}{l}\mathrm{A}_{0} \text { : derrame mínimo, } \\
\text { facilmente drenado }(<10 \\
\mathrm{mm} \text { em decúbito lateral) }\end{array}$ & e & $\begin{array}{l}\mathrm{B}_{\mathrm{x}}: \text { cultura e } \\
\text { coração de Gram } \\
\text { indeterminadas }\end{array}$ & e & $\mathrm{C}_{\mathrm{x}}: \mathrm{pH}$ indeterminado & 1 & Muito baixo & Não \\
\hline $\begin{array}{l}\mathrm{A}_{1}: \text { derrame pequeno a } \\
\text { moderado (> } 10 \mathrm{~mm} \text { e } \\
\text { menor que metade do } \\
\text { hemitórax) }\end{array}$ & e & $\begin{array}{l}\mathrm{B}_{0}: \text { cultura e } \\
\text { coração de gram } \\
\text { negativas }\end{array}$ & e & $\begin{array}{l}\mathrm{C}_{0}: \mathrm{pH} \geq 7.20 \mathrm{ou} \\
\text { [glicose] }>60 \mathrm{mg} / \mathrm{dL}\end{array}$ & 2 & Baixo & Não \\
\hline \multirow[t]{2}{*}{$\begin{array}{l}\mathrm{A}_{2} \text { : derrame extenso } \\
\text { (maior que metade do } \\
\text { hemitórax) ou derrame } \\
\text { loculado ou derrame com } \\
\text { espessamento pleural }\end{array}$} & ou & $\begin{array}{l}\mathrm{B}_{1}: \text { cultura e } \\
\text { coração de Gram } \\
\text { positivas }\end{array}$ & ou & $\begin{array}{l}\mathrm{C}_{1}: \mathrm{pH}<7.20 \text { ou [gli- } \\
\text { cose }]<60 \mathrm{mg} / \mathrm{dL}\end{array}$ & 3 & Moderado & Sim \\
\hline & & $\mathrm{B}_{2}$ : pus & & & 4 & Elevado & Sim \\
\hline
\end{tabular}

A análise bacterioscópica do líquido pleural, na maior parcela dos casos, não permite a identificação dos agentes patogênicos envolvidos, sobretudo pela antibioticoterapia empiríca instituída na ocasião da coleta do líquido ${ }^{9}$. Estudos clássicos mostram a predominância de microorganismos gram-positivos aeróbios, sobretudo Streptococcus pneumoniae (36\%), seguido de $S$. aureos e outros tipos de Streptococcus ${ }^{18}$. Microorganismos gramnegativos aeróbios mais freqüentemente encontrados incluem E. coli, K. pneumonae e H. influenzae ${ }^{18}$. Já nos pacientes portadores de pneumonia nosocomial, observa-se mais freqüentemente Staphylococcus (46\%), dos quais a $28 \%$ são $S$. aureus resistentes a meticilina e enterobactérias, sendo organismos anaeróbios encontrados em $5 \%$ dos $\operatorname{casos}^{19}$. No Brasil, não se encontram casuísticas sobre a microbiota do DPP em adultos. Em pacientes pediátricos no nosso meio, as poucas séries existentes relatam com maior freqüência $S$. pneumonae (38\%), S. aureus 
Waisberg et al. Conduta cirúrgica do derrame pleural parapneumônico em adultos.

(13\%) e $H$. influenzae $(8 \%)^{20}$. Por fim, salienta-se a importância da hemocultura, pois, embora raramente se apresente positiva (12 a $30 \%$ dos casos), é muitas vezes a única prova microbiológica do processo infeccioso ${ }^{19,20}$.

\section{Diagnóstico radiológico}

A radiografia de tórax usualmente confirma a suspeita clínica de DPP, com existência ou não de consolidação parenquimatosa ${ }^{1,3,10}$. Geralmente, loculações e níveis hidro-aéreos estão presentes. A radiografia de perfil é útil na detecção de pequenos derrames, porém sua sensibilidade é limitada ${ }^{16}$. Prossegue-se com o ultra-som (US), mais sensível, em que a presença material hiperecogênico e de mudanças na forma com a expiração sugerem empiema ${ }^{16}$. Além disso, ele também permite a visualização de septações, indica local preciso para punção e ainda sugere a característica do líquido pleural: DPP complicados estão associados a faixas de material ecogênico sobrenadante que movemse com a respiração e sugerem cronicidade ${ }^{3,16}$. Seu uso rotineiro deve ser, portanto, incentivado ${ }^{3}$. A tomografia computadorizada de tórax (TC) proporciona a diferenciação entre empiema pleural e abscesso pulmonar ou mediastinal, bem como a detecção de espessamento pleural e de loculações paramediastinais ou interlobares, além de estimar a cronicidade do quadro e auxiliar na detecção da causa de base, o que é importante para definir a estratégia de tratamento ${ }^{1,10,16}$. É um exame imperativo para estadiamento de quadros mais complexos e planejamento cirúrgico.

\section{Opções terapêuticas}

O tratamento para o DPP, assim como para outras formas de derrame pleural, baseia-se em três princípios: diagnóstico precoce, antibioticoterapia apropriada e drenagem adequada do espaço pleural $^{1-5}$. O tratamento apresenta os seguintes objetivos: eliminação do DPP, reexpansão pulmonar, restauração da mobilidade da parede torácica e do diafragma, normalização da função respiratória, eliminação das complicações e da cronicidade e redução do tempo de internação ${ }^{1-5}$. Na literatura, nota-se que a maior fonte de controvérsias consiste na escolha do método cirúrgico de drenagem (Tabela 3). Abaixo descrevemos cada método, bem como suas vantagens e desvantagens, além dos resultados obtidos por diferentes autores com a utilização de cada um deles.

TABELA 3. Opções terapêuticas. VATS, video-assisted thoracoscopic surgery

\begin{tabular}{l|l}
\hline Opções terapêuticas para tratamento de derrame pleural parapneumônico \\
\hline \multicolumn{2}{c}{ Toracocentese terapêutica } \\
Toracostomia com drenagem & Fechada \\
\multicolumn{2}{c}{ Instilação de fibrinolíticos } \\
Decorticação cirúrgica & VATS \\
\end{tabular}

\section{Antibioticoterapia e medidas gerais}

Por se tratar de uma infecção, a todo paciente portador de DPP deve ser prescrita antibioticoterapia. Inicialmente, recomenda-se a via endovenosa. A escolha deve ser inicialmente empírica e posteriormente baseada nos resultados de culturas obtidas a partir de amostras de sangue e líquido pleural. Organismos anaeróbios são dificilmente detectados por cultura e muitas vezes coexistem com organismos aeróbios $^{12,15,21}$. Em casos de culturas negativas, deve-se seguir a política da comissão de infecção hospitalar local. A mudança para via oral pode ser feita somente na presença de sinais de melhora clínica e resolução da febre ${ }^{12}$. A monitorização periódica dos níveis séricos de marcadores inflamatórios, juntamente com parâmetros clínicos do paciente, constitui a melhor maneira de se avaliar a resposta ao tratamento ${ }^{21}$.

\section{Toracocentese terapêutica}

Consiste na retirada de líquido do espaço pleural utilizando-se de uma punção por agulha (Jelco ou Abocath, 14 ou 16 gauge), guiada ou não por ultra-som ${ }^{9}$. Como método diagnóstico, no qual somente cerca de $10 \mathrm{~mL}$ de líquido é puncionado, é 
largamente empregada para determinação da fase do DPP, constituindo na maioria das vezes o primeiro procedimento realizado ${ }^{1}$. É comum a realização de toracocentese terapêutica (TT) concomitante à diagnóstica, quando se procura retirar a maior quantidade de líquido possível ${ }^{9}$. Podem ocorrer as seguintes complicações durante o procedimento: tosse, reação vasovagal com bradicardia e hipotensão, hematoma de parede torácica, hemotórax, infecção da cavidade pleural, pneumotórax, fístula cutâneopleural ou broncopleural (cerca de 3 a 19\% dos (casos) $)^{22}$.

A TT é o método menos invasivo de abordagem do espaço pleural. Contudo, a utilização de repetidas TT para tratamento de DPP é atualmente discutível. Há grande variação nas taxas de sucesso relatadas em séries prospectivas $(41-90 \%)^{23,24}$ e $95,4 \%$ em retrospectivas ${ }^{25}$. Isso se deve às diferentes fases do processo de DPP nas quais se encontravam os pacientes nas diversas séries. Empiricamente, estágios mais precoces cursam com melhor prognóstico, ainda mais com ausência de loculações. Envolvendo apenas DPP de fases II e III, Simmers et al. ${ }^{26}$ obtiveram um índice de cura de $86 \%$ em 29 pacientes. Contudo, o tempo de internação foi muito prolongado e o número de procedimentos realizados foi bastante elevado (médias de 31 dias e 7,7 toracocenteses, respectivamente). Por outro lado, Mandal et al. ${ }^{27}$ e Lemmer et al. ${ }^{28}$ reportaram um índice de sucesso de $25 \%$ e $36 \%$, respectivamente, para casos semelhantes. Storm et al. ${ }^{29}$ realizaram um trabalho comparativo retrospectivo e não controlado entre TT repetidas (pacientes do serviço de pneumologia clínica) e toracostomia com drenagem fechada (doentes do departamento de cirurgia), obtendo uma taxa de sucesso de $94 \%$ versus $21 \%$ $(p<0,01)$. Entretanto, questionam-se os resultados obtidos pela natureza do estudo e pela discrepância entre os grupos de pacientes. Mais recentemente, Sasse et al. ${ }^{30}$, em um modelo experimental de DPP complicado ou empiema induzidos em coelhos, concluíram que a TT diária é ao menos tão efetiva quanto a toracostomia com drenagem fechada, por meio das taxas de mortalidade obtidas em cada grupo, desde que iniciada até 48 horas da indução do quadro. Não existem relatos, contudo, da utilização desta conduta na prática clínica.

\section{Toracostomia com drenagem fechada}

A utilização da toracostomia com drenagem fechada (TDF) está bem estabelecida em DPP complicados ou extensos (mais que metade do hemitórax envolvido) $)^{1,5}$ e tem sido o método mais utilizado para abordagem inicial do DPP 5 . Corresponde à inserção de dreno torácico, que deve ser efetuada preferencialmente na linha hemiaxilar, a fim de se evitar as grandes massas musculares da parede torácica, na borda superior do arco costal ${ }^{1}$. Possíveis complicações incluem: hemorragia e neuralgia intercostal por lesão de feixe vásculo nervoso, enfisema de subcutâneo e perfuração de órgãos abdominais ou torácicos ${ }^{9}$. Novamente se observa relativa variação nas taxas de sucesso relatadas na literatura, 35-62\% em estudos prospectivos ${ }^{23,24}$ e $66 \%$ em retrospectivos ${ }^{25,31}$. A inserção do dreno guiada por método de imagem (US ou TC) está relacionada à maior índice de sucesso, visto que espessamento pleural e loculações podem complicar sua inserção ${ }^{3}$. Consagrou-se o uso de drenos de maior calibre (28$36 \mathrm{~F})$, pois se temia a obstrução de drenos menores. Entretanto, é o correto posicionamento do dreno o fator central para sucesso do procedimento 5 . Demonstraram-se índices de sucesso de 57 a 90\% em séries utilizando pigtails de 8 a $12 \mathrm{~F}$ ou cateteres de Malecot de 10 a $14 \mathrm{~F}$ guiados por método de imagem $16,23,31-33$.

É imperiosa a avaliação do sucesso do procedimento após 24 horas, por meio de melhora clínica ou radiológica ${ }^{1,5}$. Se não houver progressão nesse período, ou a drenagem da cavidade (por loculação do líquido pleural, alocação insatisfatória do dreno ou encarceramento pulmonar) ou a antibioticoterapia (não cobertura ou resistência bacteriana) estão inadequadas. No primeiro caso, ultra-som e tomografia computadorizada devem ser realizados para determinação do motivo e conduta a ser seguida. Não se deve postergar a implementação de métodos mais invasivos, o que resulta em maior tempo de internação e maior morbimortalidade, em virtude da passagem do DPP para fases mais avançadas ${ }^{34}$. Em vista disso, é crucial determinar fatores preditores de ineficiência da TDC. A presença de multiloculações, de encarceramento pulmonar ou de fistula pleuropulmonar indicam abordagem mais agressiva ${ }^{35}$, como observado na série de Thourani et al. ${ }^{31}$, em que multiloculações foram responsáveis por $78 \%$ das falhas de TDF.

\section{Instilação de fibrinolíticos}

Consiste na instilação de agentes fibrinolíticos, uroquinase (UK), t-PA (ativador de plasminogênio tecidual) ou mais comumente estreptoquinase (EK) na cavidade pleural. Sua principal função é a lise de septações que geram a loculação de derrames pleurais e dificultam a ação de antibióticos e o esvaziamento da cavidade. Além disso, estas septações constituem ainda o substrato para migração e proliferação de fibroblastos e deposição 
Waisberg et al. Conduta cirúrgica do derrame pleural parapneumônico em adultos.

de colágeno. Não há consenso na literatura quanto à utilização de agentes fibrinolíticos para tratamento de DPP, porém duas abordagens são mais comumente consideradas: instilação no momento de inserção de dreno torácico, independentemente da presença de loculações, a fim de se evitar sua formação, ou somente após a confirmação de septações ${ }^{9}$.

Tal método foi inicialmente descrito por Tillet et al. ${ }^{36}$, utilizando injeção intrapleural de estreptoquinase (fibrinolítico) e estrepdornase (DNAase) extraídas diretamente de culturas de streptococcus $\alpha$-hemolítico (grupo C de Lancefield). Entretanto, essa terapia foi abandonada em virtude de efeitos colaterais que incluíam febre, prostação e leucocitose ${ }^{37}$, causados por impurezas alergênicas presentes nas soluções. $\mathrm{O}$ advento de EK purificada e do descobrimento da UK (extraída da urina humana) renovaram o interesse por esse método de drenagem a partir da década de 1980. Diversos estudos não-controlados reportando a utilização de fibrinolíticos foram produzidos, com uma taxa de sucesso amplamente variável (44 a $100 \%)^{38-40}$. Em séries retrospectivas comparando diversos métodos terapêuticos, apenas a de Ozol et al. ${ }^{25}$ relata uso de fibrinolíticos (EK), com uma taxa de sucesso de $78,5 \%$, estatisticamente maior que a de TCD $(65,9 \%)$. Em um estudo prospectivo duplocego de Bouros et al. ${ }^{41}$, compararam-se EK e UK em relação à eficiência em casos refratários à TDF.
Em 28\% dos pacientes instilados com EK, ocorreu moderado aumento de temperatura corpórea, sendo que em dois casos (8\%) foi necessária a troca de EK por UK. Tais efeitos não foram observados no grupo submetido à UK. Apesar de sua menor piogenicidade, pois é proveniente da urina humana, o custo de UK foi cerca de duas vezes maior que o da EK. A eficácia dos dois agentes, no entanto, foi semelhante, com uma taxa de sucesso de $92 \%$.

Encontram-se diversos estudos prospectivos randomizados controlados na literatura analisando a eficácia de agentes fibrinolíticos. Os dados referentes a eles são apresentados na Tabela 4. A maioria deles demonstra resultados positivos com uso dessa terapia: maior volume drenado ${ }^{42-45}$, menor tempo de permanência de dreno ${ }^{44,45,47}$, baixa incidência de complicações ${ }^{42,43,45-47}$, menor tempo de internação ${ }^{44,45,47}$, menor índice de mortalidade ${ }^{47}$ e maior taxa de sucesso ${ }^{44-47}$ quando comparado à TDF simples ${ }^{42,47}$ ou instilação de solução salina (placebo $)^{43-46}$. Assim, o uso de tais agentes estaria indicado para casos de fase II resistentes à TDF, ou que apresentassem multiloculações e baixa probabilidade de resposta à inserção do dreno. Uma ressalva deve ser feita em relação ao estudo de Diacon et al. ${ }^{46}$ : os resultados foram obtidos com uso de fibrinolíticos prolongado por 7 dias, ao invés do tradicional período de três $\mathrm{s}^{19,42-45,47}$.

TABELA 4. Estudos prospectivos randomizados controlados que comparam instilação de fibrinolíticos

\begin{tabular}{|c|c|c|c|c|c|c|c|c|}
\hline & $\begin{array}{c}\mathrm{N}^{\circ} \mathrm{de} \\
\text { pacientes }\end{array}$ & $\begin{array}{l}\text { Fase } \\
\text { do } \\
\text { DPP }\end{array}$ & $\begin{array}{l}\text { Taxa de } \\
\text { sucesso }\end{array}$ & $\begin{array}{c}\text { Tempo de } \\
\text { dreno (dias) }\end{array}$ & $\begin{array}{l}\text { Volume } \\
\text { drenado }\end{array}$ & $\begin{array}{c}\text { Tempo de } \\
\text { internação }\end{array}$ & $\begin{array}{c}\text { Taxa de } \\
\text { complicação }\end{array}$ & $\begin{array}{c}\text { Taxa de } \\
\text { óbito }\end{array}$ \\
\hline Chin et al. ${ }^{42}$ & $\begin{array}{l}23 \mathrm{EK} \\
29 \mathrm{TDF}\end{array}$ & $\begin{array}{l}\text { Fases } \\
\text { Il e III }\end{array}$ & $\begin{array}{l}88 \% \text { EK } \\
96 \% \text { TDF }\end{array}$ & $\begin{array}{c}12 \text { dias EK } \\
12 \text { dias TDF }\end{array}$ & $\begin{array}{l}\text { 2L EK } \\
1 \mathrm{LDF} *\end{array}$ & $\begin{array}{c}22 \text { dias EK } \\
21 \text { dias TDF }\end{array}$ & $\begin{array}{c}0 \% \text { EK } \\
0 \% \text { TDF }\end{array}$ & $\begin{array}{c}9 \% \text { EK } \\
24 \% \text { TDF }\end{array}$ \\
\hline Davies et al. ${ }^{43}$ & $\begin{array}{c}12 \mathrm{EK} \\
12 \mathrm{P}\end{array}$ & $\begin{array}{c}\text { Fase } \\
\text { II }\end{array}$ & $\begin{array}{l}100 \% \text { EK } \\
75 \% \text { TDF }\end{array}$ & $\mathrm{NI}$ & $\begin{array}{l}\text { 391ml EK } \\
124 \mathrm{ml} \mathrm{P}^{*}\end{array}$ & $\begin{array}{c}16 \text { dias EK } \\
13 \text { dias } P\end{array}$ & $\begin{array}{c}0 \% \mathrm{EK} \\
0 \% \mathrm{P}\end{array}$ & $\begin{array}{c}0 \% \mathrm{EK} \\
0 \% \mathrm{P}\end{array}$ \\
\hline aBouros et al. ${ }^{44}$ & $\begin{array}{c}15 \text { UK } \\
16 P\end{array}$ & $\begin{array}{l}\text { Fases } \\
\text { II e III }\end{array}$ & $\begin{array}{c}86,5 \% \text { UK } \\
25 \% \mathrm{P}^{*}\end{array}$ & $\begin{array}{l}8 \text { dias UK } \\
12 \text { dias } P^{*}\end{array}$ & $\begin{array}{l}\text { 1240ml UK } \\
350 \mathrm{ml} \mathrm{P*}\end{array}$ & $\begin{array}{l}13 \text { dias UK } \\
18 \text { dias } P^{*}\end{array}$ & $\begin{array}{c}6,6 \% \text { UK } \\
0 \% \mathrm{P}\end{array}$ & $\begin{array}{c}0 \% \text { UK } \\
0 \% \mathrm{P}\end{array}$ \\
\hline $\begin{array}{l}\text { Tuncozgur et } \\
\text { al. }{ }^{45}\end{array}$ & $\begin{array}{l}24 \text { UK } \\
25 \mathrm{P}\end{array}$ & $\begin{array}{c}\text { Fase } \\
\text { II }\end{array}$ & $\begin{array}{c}70,9 \% \text { UK } \\
40 \% P^{*}\end{array}$ & $\begin{array}{l}10 \text { dias UK } \\
17 \text { dias } P^{*}\end{array}$ & $\begin{array}{l}1,8 \mathrm{~L} \text { UK } \\
0,8 \mathrm{~L} \mathrm{P}^{*}\end{array}$ & $\begin{array}{l}14 \text { dias UK } \\
21 \text { dias } P^{*}\end{array}$ & $\begin{array}{c}0 \% \text { UK } \\
0 \% \mathrm{P}\end{array}$ & $\begin{array}{c}0 \% \text { UK } \\
0 \% \mathrm{P}\end{array}$ \\
\hline Diacon et al. ${ }^{46}$ & $\begin{array}{c}22 \mathrm{EK} \\
22 \mathrm{P}\end{array}$ & $\begin{array}{l}\text { Fases } \\
\text { II e III }\end{array}$ & $\begin{array}{l}86,4 \% \text { EK } \\
54,5 \% P^{*}\end{array}$ & $\begin{array}{c}7 \text { dias } \mathrm{EK} \\
6 \text { dias } P\end{array}$ & $\begin{array}{c}2,07 \mathrm{EK} \\
1,71 \mathrm{P}\end{array}$ & $\begin{array}{l}\text { 10,5 dias } \\
\text { EK } \\
9 \text { dias } P\end{array}$ & $\begin{array}{c}0 \% \mathrm{EK} \\
0 \% \mathrm{P}\end{array}$ & $\begin{array}{c}9,9 \% \text { EK } \\
9,9 \% \mathrm{P}\end{array}$ \\
\hline Maskell et al. ${ }^{19}$ & $\begin{array}{c}208 \text { EK } \\
222 \mathrm{P}\end{array}$ & $\begin{array}{c}\text { Fase } \\
\text { II }\end{array}$ & $\begin{array}{c}84 \% \text { EK } \\
82 \% \mathrm{P}\end{array}$ & $\mathrm{NI}$ & $\mathrm{NI}$ & $\begin{array}{c}12 \text { dias EK } \\
13 \text { dias } P\end{array}$ & $\begin{array}{l}7 \% \text { EK } \\
3 \% P^{*}\end{array}$ & $\begin{array}{c}14 \% \text { EK } \\
16 \% \mathrm{P}\end{array}$ \\
\hline Misthos et al. ${ }^{47}$ & $\begin{array}{c}57 \mathrm{EK} \\
70 \mathrm{TDF}\end{array}$ & $\begin{array}{c}\text { Fase } \\
\text { II }\end{array}$ & $\begin{array}{c}87,7 \% \text { EK } \\
67,1 \% \\
\text { TDF* }^{\star}\end{array}$ & $\begin{array}{c}7 \text { dias EK } \\
15 \text { dias } \\
\text { TDF* }^{*}\end{array}$ & $\mathrm{NI}$ & $\begin{array}{c}7 \text { dias EK } \\
15,5 \text { dias } \\
\text { TDF* }^{\star}\end{array}$ & $\begin{array}{c}0 \% \text { EK } \\
0 \% \mathrm{P}\end{array}$ & $\begin{array}{c}\text { 1,7\% EK } \\
\text { 4,2\% TDF* }\end{array}$ \\
\hline
\end{tabular}

Legenda: NI - não informado; * - estatisticamente significante, p < 0,05; a - pacientes analisados no estudo são refratários à TDF; EK estreptoquinase; UK - uroquinase; TDF - toracostomia com drenagem fechada; e P - placebo, isto é, instilação de solução salina. Considerouse taxa de sucesso como a resolução do quadro com a utilização do método, sem necessidade de procedimentos mais invasivos 
Não obstante os favoráveis resultados reportados em tais séries, o valor dos agentes fibrinolíticos foi questionado a partir do trabalho MIST-1 (19), o maior estudo prospectivo, duplocego, randomizado e controlado abordando o tema. O grupo de fibrinolítico apresentou evolução semelhante ao grupo placebo, porém com maior taxa de complicações (hemorragia, intrapleural ou generalizada, dor torácica, febre e rash cutâneo). Contudo, o desenho do estudo foi cercado de polêmica devido ao grande número de centros envolvidos (52), muitos dos quais careciam de equipe cirúrgica especializada e contribuíram com um pequeno número de pacientes. Ademais, o volume de líquido drenado não foi relatado, gerando dúvidas a respeito da eficácia da técnica de drenagem utilizada, e suspeita-se que houve atraso no envio de material (placebo ou fibrinolítico) para os diversos centros, gerando heterogeneidade no método.

Conforme apontado no MIST-1, o motivo para a eficácia reduzida de fibrinolíticos seria a ausência de DNAase nas soluções empregadas atualmente, presente nos estudos iniciais dessa técnica ${ }^{36,38}$. O único benefício do uso de fibrinolíticos isoladamente seria a lise de septações. Eles não exercem efeito sobre a viscosidade do líquido presente, que se muito elevada, impossibilita drenagem eficiente do espaço pleural. Light et al. ${ }^{37}$ e Simpson et al. ${ }^{48}$ demonstraram que soluções de varidase (combinação de EK e streptodornase purificadas) reduzem a viscosidade de pus in vitro. Simpson et al. ${ }^{49}$ publicaram um relato de caso em que houve resolução de quadro de DPP fase II resistente a instilação de EK através da utilização de DNAase recombinante humana. Entretanto, não existe na literatura estudos comparando a utilização de DNAase e fibrinolíticos in vivo, apesar de se encontrar em andamento um ensaio clínico multicêntrico no Reino Unido abordando o tema ${ }^{3}$.

\section{Decorticação cirúrgica}

O termo decorticação é derivado do latim e significa retirada de córtex ou "casca" envolvendo o pulmão. Classicamente, a operação consiste na remoção de uma camada fibrótica que envolve a pleura visceral e restringe a expansão pulmonar (fibrotórax) $)^{9}$. A "deloculação", isto é, a limpeza da cavidade pleural nos casos de DPP fibrinopurulento pela retirada de septações fibrosas, não constitui uma decorticação propriamente dita, pois não há tempo para ocorrência de encarceramento pulmonar. Para efeito prático, entretanto, é comum a aceitação de ambas como um procedimento terapêutico único². Originalmente, a decorticação é realizada por meio de toracotomia póstero-lateral ${ }^{2}$. Todavia, o advento de técnicas cirúrgicas menos invasivas na última década do século XX possibilitou o desenvolvimento da cirurgia torácica vídeo-assitida (VATS).

\section{a) Video-assisted thoracoscopic surgery (VATS)}

Consiste na realização de dois ou três orifíicos na parede torácica, com a inserção de óptica com fonte de luz própria em um deles, sendo os outros destinados ao uso de pinças e aspirador. A literatura abordando os resultados obtidos por essa técnica é extremamente vasta. A Tabela 5 mostra os principais resultados de séries de casos retrospectivas ${ }^{52-62}$. Tais dados corroboram o consenso geral de que o uso de VATS está fortemente indicado para casos de fase II refratários à TDF, em que ainda não existe encarceramento pulmonar importante, sendo necessário apenas a deloculação da cavidade para permitir a expansão pulmonar. De fato, a taxa de sucesso nessa situação é próxima de 100\% (96,5$100 \%)^{53,56,58,61}$. Quando especificado, a maioria ${ }^{54,58,59}$ ou todos os pacientes ${ }^{52,53,55,56,61}$ já haviam sido submetido à TDF, sem resolução da doença.

TABELA 5. Principais resultados obtidos em séries retrospectivas no tocante à utilização de VATS (Video-assisted thoracoscopic surgery)

\begin{tabular}{|c|c|c|c|c|c|c|c|}
\hline & $\begin{array}{c}\mathrm{N}^{\circ} \text { de } \\
\text { pacientes }\end{array}$ & $\begin{array}{l}\text { Proporção de } \\
\text { casos fase III }\end{array}$ & $\begin{array}{c}\text { Tempo } \\
\text { de pré- } \\
\text { operatório }\end{array}$ & $\begin{array}{c}\text { Tempo } \\
\text { de pós- } \\
\text { operatório }\end{array}$ & $\begin{array}{l}\text { Tempo de } \\
\text { dreno }\end{array}$ & $\begin{array}{c}\text { Taxa de } \\
\text { complicações }\end{array}$ & mortalidade \\
\hline $\begin{array}{l}\text { Lawrence } \\
\text { et al. }{ }^{54}\end{array}$ & $\begin{array}{c}30 \text { VATS } 12 \\
\text { TO }\end{array}$ & $\mathrm{NI}$ & $\begin{array}{c}\text { 13,7 dias } \\
\text { VATS } \\
11,5 \text { dias TO }\end{array}$ & $\begin{array}{l}\text { 5,3 dias VATS } \\
\text { 10,3 dias TO * }\end{array}$ & $\begin{array}{l}4 \text { dias } \\
\text { VATS } \\
8,5 \text { dias } \\
\text { TO* }\end{array}$ & $\begin{array}{l}\text { 0\% VATS } \\
0 \% \text { TO }\end{array}$ & $\begin{array}{l}\text { 0\% VATS } \\
0 \% \text { TO }\end{array}$ \\
\hline $\begin{array}{l}\mathrm{Luh} \text { et } \\
\text { al. }{ }^{58}\end{array}$ & $\begin{array}{l}194 \text { VATS } \\
40 \text { TO }\end{array}$ & $\begin{array}{c}36,08 \% \text { VATS } \\
47,5 \% \text { TO * }\end{array}$ & $\begin{array}{c}11,4 \text { dias } \\
\text { VATS } \\
18,4 \text { dias TO * }\end{array}$ & $\begin{array}{l}\text { 7,2 dias VATS } \\
20,1 \text { dias TO * }\end{array}$ & $\mathrm{NI}$ & $\begin{array}{c}5,6 \% \text { VATS } \\
20 \% \text { TO * }\end{array}$ & $\begin{array}{c}2 \% \text { VATS } 10 \% \\
\text { TO * }\end{array}$ \\
\hline $\begin{array}{l}\text { Roberts } \\
\mathrm{Jr}^{60}\end{array}$ & $\begin{array}{l}66 \text { VATS } \\
106 \text { TO }\end{array}$ & $\mathrm{NI}$ & $\begin{array}{l}5 \text { dias VATS } \\
7 \text { dias TO * }\end{array}$ & $\begin{array}{l}12 \text { dias VATS } \\
17 \text { dias TO }\end{array}$ & $\begin{array}{c}8 \text { dias } \\
\text { VATS } \\
13 \text { dias TO }\end{array}$ & $\begin{array}{l}9 \% \text { VATS } \\
21 \% \text { TO * }\end{array}$ & $\begin{array}{l}0 \% \text { VATS } \\
10 \% \text { TO* }\end{array}$ \\
\hline
\end{tabular}

NI - não informado. A taxa de sucesso corresponde à resolução do quadro sem necessidade de toracotomia no intra ou pós-operatório, enquanto a de recorrência indica necessidade de reabordagem do espaço pleural por VATS ou métodos menos invasivos 
Waisberg et al. Conduta cirúrgica do derrame pleural parapneumônico em adultos.

Os motivos para conversão para o procedimento aberto incluem: lesão ao diafragma $(0,9 \%)^{59}$, laceração pulmonar extensa $(0,9 \%)^{59}$ e principalmente impossibilidade de se obter expansão pulmonar adequada devido à decorticação deficiente $(5,4 \%)^{59}$, o que explica o índice de sucesso menor da VATS em casos de fase III, em que é necessário remover o espessamento pleural e não apenas limpar a cavidade. De fato, tal taxa é mais modesta nas séries em que incluem casos de fase III, embora algumas delas não especifiquem quantos pacientes pertenciam a cada categoria ${ }^{54,57,60}$. Naquelas que o fazem, observam-se índices menores para tais casos, mas ainda sim consideráveis, variando de 54 a 82,8\% ${ }^{52,53,58,59,62}$, sugerindo que a diminuição da carga bacteriana e de líquido inflamatório abaixo de um nível crítico associados a uma decorticação não extremamente completa, mas que permita expansão pulmonar suficiente para tocar a parede torácica e evitar espaço residual, são suficientes para a resolução do quadro. Entretanto, o estudo de Roberts $\mathrm{Jr}^{60}$ distancia-se da tendência reportada pelas outras séries, apontando uma taxa de sucesso para VATS de apenas 38,7\%. Isso se deve à metodologia do trabalho, que estabelecia que na constatação intraoperatória de espessamento pleural o procedimento era prontamente convertido à toracotomia, sem que se tentasse a resolução do quadro. No tocante ao estudo de Kim et al. ${ }^{57}$, mesmo com a inclusão de casos de fase III, a taxa de sucesso $(92,8 \%)$ permaneceu semelhante à de outras séries de casos de fase II somente, provavelmente devido à utilização de instrumental endoscópico dedicado para a remoção de pleural visceral (endoscopic shaver system), de disponibilidade reduzida.

Na maior série deste tipo na literatura, Luh et al. ${ }^{58}$ demostraram que o desempenho de VATS em casos de fase III é menor do que em casos II, apesar de que esse fato é intuitivo pela diferença de gravidadade dos pacientes. Foram observadas maiores taxas de conversão (5 vs $21,3 \%$ ) e de recorrência (4,8 vs 10\%), maior tempo de pósoperatório intrahospitalar (9,1 dias vs 18,5 dias), maior incidência de complicações $(6,2$ vs $11,2 \%)$ e maior taxa de mortalidade (2,1 vs 5,6\%). O tempo entre o diagnóstico de DPP e intervenção cirúrgica foi maior nos casos de fases III (12,5 vs 17,2 dias), sugerindo que a cronicidade e o postergar do tratamento adequado determinam terapêutica mais invasiva.

Pelas baixas taxas de complicações apontadas $\left(0^{52-55,57,61}-11,7 \%{ }^{62}\right)$, nota-se que 0 procedimento video-assistido é seguro. Elas podem incluir enfisema de subcutâneo $(2,6 \%)^{58}$, hemorragia $\left(0,8 \%{ }^{56}, 1,8^{59}\right.$ e $\left.3 \%^{58}\right)$, infecção de ferida operatória $(2,6 \%)^{58}$, colapso pulmonar $(3 \%)^{56}$ pneumotórax prolongado $\left(0,8^{56}, 5,4 \%^{59}\right.$ e $\left.5,8 \%{ }^{62}\right)$ e lesão esofágica $(5,8 \%)^{62}$. Pela taxa de recorrência também reduzida $\left(0^{52-54,57,60-62}\right.$ a $\left.6,8 \%{ }^{58}\right)$, verifica-se que é um procedimento efetivo. Em nenhuma das séries, ocorreu óbito intra-operatório, sendo que comorbidades foram quase sempre responsáveis pelos índices de mortalidade não-nulos.

Algumas das séries apontadas na Tabela 5 também compararam de maneira retrospectiva os resultados de VATS e de toracotomia realizada nos casos em que houve conversão. Tais dados são mostrados na Tabela 6 e mostram que VATS cursa com menor tempo de permanência de dreno no pósoperatório ${ }^{54}$, com alta hospitalar mais precoce ${ }^{54,58}$ e com menores taxas de complicações ${ }^{58,60}$ e de mortalidade ${ }^{58,60}$. Também se verificou que os casos convertidos apresentam maior proporção de casos em fase $1 \mathrm{II}^{58}$ e maior tempo entre o diagnóstico e tratamento cirúrgico ${ }^{58,60}$, sugerindo que a VATS possui maior probabilidade de sucesso em casos indicados mais precocemente.

TABELA 6. Principais resultados de séries retrospectivas que comparam VATS (Video-assisted Thoracoscopic Surgery) e TO (toracotomia) realizadas em casos convertidos

\begin{tabular}{|c|c|c|c|c|c|c|c|c|}
\hline & $\begin{array}{c}\mathrm{N}^{\circ} \text { de } \\
\text { pacientes }\end{array}$ & & $\begin{array}{l}\text { Tempo de } \\
\text { operação } \\
\text { (min) }\end{array}$ & $\begin{array}{l}\text { Tempo } \\
\text { de pré- } \\
\text { operatório }\end{array}$ & $\begin{array}{c}\text { Tempo de pós- } \\
\text { operatório } \\
\text { (dias) }\end{array}$ & $\begin{array}{c}\text { Tempo de } \\
\text { dreno (dias) }\end{array}$ & $\begin{array}{c}\text { Taxa de } \\
\text { complicação }\end{array}$ & Taxa de óbito \\
\hline${ }^{a}$ Mackinlay ${ }^{63}$ & $\begin{array}{l}31 \text { VATS } \\
33 \text { TO }\end{array}$ & II & $\begin{array}{l}123 \text { VATS } \\
119 \text { TO }\end{array}$ & $\begin{array}{c}11,4 \text { dias } \\
\text { VATS } \\
17,5 \text { TO}^{*}\end{array}$ & $\begin{array}{l}\text { 6,7 VATS } \\
11,6 \mathrm{TO}^{*}\end{array}$ & $\begin{array}{c}\text { 4,2 VATS } \\
\text { 6,1 TO* }\end{array}$ & $\begin{array}{c}16,1 \% \text { VATS } \\
15,1 \% \text { TO }\end{array}$ & $\begin{array}{c}3,2 \% \text { VATS } \\
3 \% \text { TO }\end{array}$ \\
\hline${ }^{\mathrm{b}} \mathrm{Chan}^{64}$ & $\begin{array}{l}41 \text { VATS } \\
36 \text { TO }\end{array}$ & $\begin{array}{l}\text { II } \\
\text { III }\end{array}$ & $\begin{array}{l}150 \text { VATS } \\
228 \text { TO}^{*}\end{array}$ & $\mathrm{NI}$ & $\begin{array}{l}16 \text { VATS } \\
21 \text { TO* }^{*}\end{array}$ & $\begin{array}{l}\text { 7,9 VATS } \\
\text { 8,7 TO }\end{array}$ & $\begin{array}{c}9,8 \% \text { VATS } \\
\text { 13,9\% TO }\end{array}$ & $\mathrm{NI}$ \\
\hline${ }^{\mathrm{c} P o d b i e l s k i}{ }^{65}$ & $\begin{array}{l}16 \text { VATS } \\
14 \text { TO }\end{array}$ & $\begin{array}{l}\text { II } \\
\text { III }\end{array}$ & $\begin{array}{l}76 \text { VATS } \\
125 \text { TO}^{*}\end{array}$ & $\begin{array}{c}11,4 \text { dias } \\
\text { VATS } \\
\text { 16,8 dias TO* }\end{array}$ & $\begin{array}{c}17,6 \text { VATS } \\
10 \text { TO }\end{array}$ & $\begin{array}{c}\text { 4,7 VATS } \\
\text { 8,3 TO** }\end{array}$ & $\begin{array}{c}6,25 \% \text { VATS } \\
7,1 \% \text { TO }\end{array}$ & 0\% VATS 0\% TO \\
\hline${ }^{b}$ Waller ${ }^{66}$ & $\begin{array}{l}21 \text { VATS } \\
15 \text { TO }\end{array}$ & III & $\begin{array}{c}78,8 \text { VATS } \\
109 \text { TO*}^{*}\end{array}$ & $\begin{array}{c}19,1 \text { dias } \\
\text { VATS } \\
28,7 \text { dias TO }\end{array}$ & $\begin{array}{c}\text { 5,5 VATS } \\
\text { 8,4 TO* }\end{array}$ & $\mathrm{NI}$ & $\mathrm{NI}$ & $\begin{array}{c}4,7 \% \text { VATS } \\
6,6 \text { TO }\end{array}$ \\
\hline${ }^{\mathrm{c}}$ Caseli $^{75}$ & $\begin{array}{l}27 \text { VATS } \\
24 \text { TO }\end{array}$ & ॥ & $\begin{array}{c}100 \text { VATS } \\
131 \text { TO*}^{*}\end{array}$ & $\begin{array}{l}12 \text { VATS } \\
32 \text { TO }\end{array}$ & $\begin{array}{l}\text { 6,4 VATS } \\
9 \text { TO*}^{*}\end{array}$ & $\begin{array}{l}4 \text { VATS } \\
7,3 \text { TO }^{*}\end{array}$ & $\mathrm{NI}$ & $\mathrm{NI}$ \\
\hline${ }^{6}$ Cardillo ${ }^{76}$ & $\begin{array}{c}185 \text { VATS } \\
123 \text { TO }\end{array}$ & $\begin{array}{l}\text { II } \\
\text { III }\end{array}$ & $\begin{array}{l}\text { 70 VATS } \\
79.7 \text { TO}^{*}\end{array}$ & $\mathrm{NI}$ & $\begin{array}{c}\text { 8,6 VATS } \\
10 \mathrm{TO}^{*}\end{array}$ & $\mathrm{NI}$ & $\begin{array}{c}18,3 \% \text { VATS } \\
25,2 \% \text { TO }\end{array}$ & $\begin{array}{l}0 \% \text { VATS } \\
3,2 \% \text { TO }\end{array}$ \\
\hline${ }^{c}$ Shahin ${ }^{77}$ & $\begin{array}{l}32 \text { VATS } \\
19 \text { TO }\end{array}$ & III & $\mathrm{NI}$ & $\mathrm{NI}$ & $\begin{array}{c}5 \text { VATS } \\
8 \text { TO* }^{*}\end{array}$ & $\mathrm{NI}$ & $\begin{array}{l}9,3 \% \text { VATS } \\
25,9 \% \text { TO}^{*}\end{array}$ & $\begin{array}{c}\text { 0\% VATS } \\
0 \% \text { TO }\end{array}$ \\
\hline${ }^{c}$ Tong $^{78}$ & $\begin{array}{c}396 \text { VATS } \\
94 \text { TO }\end{array}$ & $\begin{array}{l}\text { II } \\
\text { III }\end{array}$ & $\begin{array}{l}97 \text { VATS } \\
155 \text { TO }^{*}\end{array}$ & $\mathrm{NI}$ & $\begin{array}{l}7 \text { VATS } \\
10 \text { TO* }^{*}\end{array}$ & $\begin{array}{l}7 \text { VATS } \\
9,7 \text { TO }\end{array}$ & $\mathrm{NI}$ & $\begin{array}{c}7,6 \% \text { VATS } \\
16,1 \% \text { TO* }\end{array}$ \\
\hline
\end{tabular}

$\mathrm{NI}$ - não informado; * - estatisticamente significante $(p<0,05)$ 
A despeito dos resultados favoráveis obtidos em tais casuísticas retrospectivas, existem estudos na literatura com foco central na comparação entre grupos de pacientes submetidos à VATS ou toraco- tomia. Seus principais resultados são expressos na Tabela 7. Em todos eles, a escolha do método a ser utilizado em cada caso baseou-se na preferência do cirurgião, quando indicada a intervenção cirúrgica.

TABELA 7. Estudos focando a comparação entre VATS (Video-assisted Thoracoscopic Surgery) e TO (toracotomia)

\begin{tabular}{|c|c|c|c|c|c|c|c|}
\hline & $\begin{array}{c}\mathrm{N}^{\circ} \text { de } \\
\text { pacientes }\end{array}$ & $\begin{array}{l}\text { Taxas de } \\
\text { sucesso }\end{array}$ & $\begin{array}{c}\text { Emprego de } \\
\text { TO }\end{array}$ & $\begin{array}{l}\text { Tempo de } \\
\text { internação } \\
\text { (dias) }\end{array}$ & $\begin{array}{l}\text { Tempo } \\
\text { de dreno } \\
\text { (dias) }\end{array}$ & $\begin{array}{c}\text { Taxa de } \\
\text { complicações }\end{array}$ & mortalidade \\
\hline Bilgin et al. ${ }^{67}$ & $\begin{array}{l}35 \text { VATS } \\
35 \text { TDF }\end{array}$ & $\begin{array}{c}82,9 \% \\
\text { VATS } \\
62,9 \% \text { TDF* }^{*}\end{array}$ & $\begin{array}{l}17,1 \% \text { VATS } \\
37,1 \% \text { TDF }^{\star}\end{array}$ & $\begin{array}{l}\text { 8,3 VATS } \\
\text { 12,8 TDF* }\end{array}$ & $\mathrm{NI}$ & $\begin{array}{c}2,8 \% \text { VATS } \\
2,8 \% \text { TDF }\end{array}$ & $\begin{array}{c}2,8 \% \text { VATS } \\
0 \% \text { TDF }\end{array}$ \\
\hline Wait et al. ${ }^{68}$ & $\begin{array}{l}11 \text { VATS } \\
9 \mathrm{EK}\end{array}$ & $\begin{array}{c}91 \% \text { VATS } \\
44 \% \text { EK* }^{*}\end{array}$ & $\begin{array}{c}\text { 0\% VATS } \\
0 \% \text { EK }\end{array}$ & $\begin{array}{l}\text { 5,8 VATS } \\
9,8 \mathrm{EK}^{*}\end{array}$ & $\begin{array}{l}\text { 8,7 VATS } \\
12,8 \mathrm{EK}^{*}\end{array}$ & $\begin{array}{c}0 \% \text { VATS } \\
0 \% \text { TDF }\end{array}$ & $\begin{array}{c}9 \% \text { VATS } \\
11 \% \text { EK }\end{array}$ \\
\hline $\begin{array}{l}\text { Petrakis et } \\
\text { al. }^{69}\end{array}$ & $\begin{array}{c}20 \text { UK + VATS } \\
\text { (GI) } 18 \text { VATS } \\
\text { (GII) }\end{array}$ & $\begin{array}{c}85 \% \text { Gl } \\
95 \% \text { Gll * }\end{array}$ & $\begin{array}{l}15 \% \mathrm{Gl} \\
5 \mathrm{Gll} \text { * }\end{array}$ & $\begin{array}{c}\text { 7,5 Gl } \\
4,5 \mathrm{Gll}^{*}\end{array}$ & $\begin{array}{l}4,5 \mathrm{Gl} \\
3,5 \mathrm{GII}\end{array}$ & $\begin{array}{c}0 \% \text { VATS } \\
0 \% \text { TDF }\end{array}$ & $\begin{array}{c}0 \% \text { VATS } \\
0 \% \text { TDF }\end{array}$ \\
\hline
\end{tabular}

NI - não informado; * - estatisticamente significante $(\mathrm{p}<0,05)$; $a$, estudo com série retrospectiva para TO e prospectiva para VATS; b estudo prospectivo; c - estudo retrospectivo

Observamos que tais estudos confirmam os resultados obtidos em séries retrospectivas no tocante ao tempo de permanência de dreno no pósoperatório ${ }^{63,65,75}$, à indicação de alta hospitalar $63,64,66,75-78$ e ao intervalo entre diagnóstico e intervenção cirúrgica ${ }^{63,65,66}$. Além disso, também foi demonstrado que a perda de sangue no intra-operatório com VATS é semelhante à com toracotomia $\left(881\right.$ vs $\left.872 \mathrm{ml}^{64}\right)$ ou menor (131 vs 313,9m/65), contrariando a concepção de que a hemostasia estaria prejudicada na VATS pelo seu caráter menos invasivo. Diferentemente dos estudos anteriores, no entanto, as taxas de mortalidade e de complicações foram semelhantes, com exceção de dois estudos ${ }^{77,78}$, o que revela que as diferenças encontradas em tais casuísticas eram devido à maior gravidade dos pacientes que necessitaram de conversão à toracotomia. 0 tempo de duração do procedimento foi menor para VATS $^{64,66,75,76,78}$, porém esse dado foi verificado apenas em algumas séries, sendo que existe grande variação nas médias de tempo reportadas $\left(42^{61}-170^{60} \mathrm{~min}\right)$, o que provavelmente é reflexo da gravidade dos casos incluídos e da influência da experiência da equipe cirúrgica.

O estudo de Chan et al. ${ }^{64}$ demonstra ainda as vantagens do procedimento por VATS sobre a toracotomia no tocante à satisfação do paciente. Por meio de questionários, verificou-se que o uso de VATS cursa com menor dor no pós-operátorio e menor incômodo com as cicatrizes. No estudo de Waller et al. ${ }^{66}$, obteve-se uma taxa de conversão geral de $58,3 \%$, que diminui conforme se elevava o número de procedimentos realizados com a técnica. Ladinois et al. ${ }^{34}$ comparam prospectivamente pacientes com quadro resolvido por VATS com aqueles que tiveram conversão. Análise multivariada identificou o tempo entre diagnóstico e intervenção cirúrgica (9,8 para VATS VS 17,3 dias para conversão) como fator preditor para conversão. A partir do $14^{\circ}$ dia de diagnóstico, essa probabilidade aumenta intensamente.

Os bons resultados obtidos com o uso de VATS e seu caráter pouco invasivo incentivaram a realização de estudos prospectivos randomizados que procuraram estabelecer o benefício da indicação cirúrgica para casos precoces (fase II), em que terapêutica mais conservadora ainda seria cabível. Os dados referentes a eles são apresentados na Tabela 8.

TABELA 8. Estudos comparativos entre VATS (Vídeo-assisted Thoracoscopic Surgery), TDF (toracostomia com drenagem fechada), EK (instilação de estreptoquinase) e VATS após falha de instilação de uroquinase (VATS + UK)

\begin{tabular}{|c|c|c|c|c|c|}
\hline Método & TT & TDF & Fibrinolíticos & VATS & Toracotomia \\
\hline Taxa de sucesso (\%) & $25^{27}-95,4^{24}$ & $35^{23}-66^{25,31}$ & $70^{42}-92^{41}$ & $38,7^{60}-100^{61}$ & $88^{24}-100^{23,66}$ \\
\hline Complicações (\%) & $0^{23-25}-10^{29}$ & $0^{23-25,42-47}-30^{29}$ & $0^{42-47}-7^{19^{* *}}$ & $0^{52-55,57,61}-16,1^{63}$ & $0^{54}-21,1^{60}$ \\
\hline Internação (dias) & $14^{25}-23^{23}$ & $13^{19,43}-26^{23}$ & $12^{19}-21^{42}$ & $4^{54}-17,6^{65}$ & $6,1^{63}-13^{60}$ \\
\hline Tempo de drenagem (dias) & Não se aplica & $9^{43}-15,5^{47}$ & $7^{47}-12^{42}$ & $3,3^{53}-10^{56}$ & $6,1^{63}-10^{60}$ \\
\hline Mortalidade (\%) & $0^{24}-25^{28}$ & $0^{43,44}-16,8^{23}$ & $0^{43,44}-9^{42}$ & $0^{56.57 .60-62}-13,3^{52}$ & $0^{54}-10^{58,60}$ \\
\hline
\end{tabular}

$\mathrm{NI}$ - não informado; * - estatisticamente significante, $\mathrm{p}<0,05$ 
Waisberg et al. Conduta cirúrgica do derrame pleural parapneumônico em adultos.

O estudo de Bilgin et al. ${ }^{67}$ demonstrou que o uso precoce de VATS determina maior índice de sucesso e menor tempo de internação quando comparado à TDF. Isso não significa que a TDF deve ser abandonada, pois é provável que nem todos os pacientes do grupo de VATS necessitassem de procedimento mais invasivo para resolução do quadro. Porém, os resultados indicam que aqueles pacientes submetidos à TDF sem indícios de melhora clínica ou radiológica se beneficiam se indicados para tratamento com VATS precocemente. Por outro lado, o estudo de Wait et al. ${ }^{68}$ mostra que o uso de fibrinolíticos posterga, ao invés de substituir, o tratamento cirúrgico para casos de derrame loculados e extensos, aumentando o custo da internação. De fato, uma taxa de $85 \%$ foi relatada no estudo retrospectivo de Bouros et al..$^{70}$ para casos refratários à terapêutica fibrinolítica. Os resultados obtidos por Petrakis et al. ${ }^{69}$ demosntram que pacientes referidos diretamente à VATS se beneficiam mais do procedimento quando comparados àqueles indicados após falha no tratamento com fibrinolíticos, inclusive com menor tempo de operação (62 vs 70 minutos, $\mathrm{p}<0,05)$.

\section{b) Toracotomia}

Originalmente, a decorticação é realizada por meio de toracostomia póstero-lateral, que apresenta relativa morbidade, mesmo com métodos de preservação muscular, em virtude da incisão e do afastamento de costelas, resultando em maior desconforto pós-operatório ${ }^{50}$. Sua principal indicação é para casos crônicos de fase III, com espessamento pleural intenso e encarceramento pulmonar. Tratase de uma técnica bem estabelecida. Seu índice de sucesso varia de $88 \%{ }^{24}$ a $100 \%{ }^{23,67}$. A incidência de complicações também é baixa, variando de $0^{54}$ a $21 \%{ }^{60}$, sendo elas as mesmas para o procedimento por VATS. Apesar de ser uma intervenção cirúrgica extensa, as taxas de mortalidade são reduzidas, entre $0^{53,63}$ a $10 \%{ }^{58,60}$.

Vários trabalhos mostram o benefício da indicação precoce de toracotomia. Mandal et al. ${ }^{24}$ mostraram um tempo de internação maior em pacientes submetidos à colocação de dreno, quando comparado ao grupo de decorticação (17 vs 14 dias), uma maior mortalidade ( $11 \%$ vs 1,3\%) e menor índice de sucesso (62\% vs $88 \%$ ). Fergunson et al. ${ }^{23}$ também obtiveram maior tempo de internação em pacientes tratados por métodos conservadores comparados à decorticação (21 vs 12 dias). Foi identificado que derrames que acometem mais de $40 \%$ do hemitórax apresentam maior probabilidade de falha com métodos conservadores (cerca de $86 \%$ ). O estudo de
Thourani et al. ${ }^{31}$ sugeriu que a decorticação precoce é o método mais efetivo e de menor custo em casos de derrames loculados. O uso de dreno nessa situação prolonga o tempo de internação (21 vs 17 dias), que ainda aumenta caso o tratamento falhe (29 dias) e apresenta menor probabilidade de sucesso. Melloni et al. ${ }^{71}$ demonstraram, através, que a ocorrência de comorbidades, duração de sintomas maiores que 60 dias e duração de tratamento conservador pouco efetivo maior que 30 dias aumentam a morbidade da decorticação. Resultados semelhantes foram obtidos por Pothula et al. ${ }^{72}$, permitindo a conclusão de que a evidência de não resolução do quadro pelos métodos conservadores implica conversão rápida para intervenção cirúrgica. Esse tipo de conduta determinou mortalidade (8\%), taxa de complicações (10\%) e tempo de internação reduzidos (7 dias).

\section{Toracostomia com drenagem aberta (TDA)}

Consiste na remoção de arcos costais e toda a espessura da parede torácica para permitir a drenagem da cavidade pleural ${ }^{2}$. Existem diversos tipos e técnicas de TDA, de acordo com a utilização de próteses ou retalhos musculares. Somente pode ser realizada em casos de encarceramento pulmonar, visto que a fibrose intensa mantém o pulmão e o mediastino fixos, evitando a ocorrência de pneumotórax ${ }^{5}$. Era o primeiro passo no controle da infecção local antes do estabelecimento de antibioticoterapia e métodos menos invasivos, porém atualmente é um procedimento de exceção, dado sua característica mutilante e longo tempo de evolução. Em séries históricas, relata-se tempo médio de 142 dias para controle do quadro infeccioso ${ }^{8}$. A rara indicação, nos tempos modernos, seria apenas para pacientes extremamente debilitados, com evolução crônica, que não podem ser submetidos à decorticação por VATS ou toracotomia ${ }^{2,5}$, uma vez que é um procedimento de baixo risco.

\section{CONCLUSÃO}

De acordo com o que foi exposto, elaboramos uma tabela que fornece um resumo dos principais resultados obtidos com cada método terapêutico para DPP nos diferentes estudos analisados (Tabela 9).

Por ser um método pouco invasivo e com complicações reduzidas, a TT, como método inicial, pode ser utilizada nos casos em que o DPP ocupe menos de um hemitórax e o líquido coletado corresponda a um DPP simples, isto é, um paciente na categoria 2 da classificação da ACCP (Tabela 2). É importante ressaltar que seus resultados são inferiores aos outros métodos terapêuticos e, mesmo nesta população selecionada, deve ser utilizada 
com cautela. A ausência de estudos controlados comparando TT repetidas com TDF ou outros métodos no DPP complicado ou empiema, além da grande variabilidade e falhas metodológicas nos trabalhos existentes, contraindicam sua utilização em casos mais avançados.

TABELA 9. Comparação entre as terapêuticas existentes para tratamento do DPP. Considerou-se a taxa de sucesso quando da resolução do quadro, sem necessidade de procedimentos adicionais

\begin{tabular}{|c|c|c|c|c|c|}
\hline Método & TT & TDF & Fibrinolíticos & VATS & Toracotomia \\
\hline Taxa de Sucesso (\%) & $25^{27}-95,4^{24}$ & $35^{23}-66^{25,31}$ & $70^{42}-92^{41}$ & $38,7^{60}-100^{61}$ & $88^{24}-100^{23,66}$ \\
\hline Complicações (\%) & $0^{23-25}-10^{29}$ & $0^{23-25,42-47}-30^{29}$ & $0^{42-47}-7^{19^{* *}}$ & $0^{52-55,57,61}-16,1^{63}$ & $0^{54}-21,1^{60}$ \\
\hline Internação (dias) & $14^{25}-23^{23}$ & $13^{19,43}-26^{23}$ & $12^{19}-21^{42}$ & $4^{54}-17,6^{65}$ & $6,1^{63}-13^{60}$ \\
\hline Tempo de drenagem (dias) & Não se aplica & $9^{43}-15,5^{47}$ & $7^{47}-12^{42}$ & $3,3^{53}-10^{56}$ & $6,1^{63}-10^{60}$ \\
\hline Mortalidade (\%) & $0^{24}-25^{28}$ & $0^{43,44}-16,8^{23}$ & $0^{43,44}-9^{42}$ & $0^{56.57 .60-62-13,3^{52}}$ & $0^{54}-10^{58,60}$ \\
\hline
\end{tabular}

${ }^{\star}$ Apenas os resultados de estudos randomizados foram considerados. TT - toracocentese terapêutica; TDF - toracostomia com drenagem fechada; VATS - Vídeo-assisted thoracoscopic surgery

O uso da TDF está bem estabelecido na literatura e na prática clínica como abordagem inicial em casos de DPP complicado ou extensos (categoria 3 da ACCP). Em meta-análise ${ }^{15}$, observase um índice de sucesso de $59.7 \%$ (95\% IC: 54,9 , $64,3 \%$ ) e de mortalidade de $8,8 \%$ (95\% IC: $6,3,12 \%$ ), superior à TT, que apresentou taxas respectivas de $53,7 \%$ (95\% IC: $46,61,3 \%$ ) e 10,3\% (95\% IC: 6,2 , $15,8 \%)$. Sugere-se a avaliação clínica e radiológica do paciente 24 horas após o procedimento ${ }^{1,5}$. $\mathrm{Na}$ ausência de melhora, a causa deve ser esclarecida, pois multiloculações, fístulas ou encarceramento requerem conduta mais agressiva ${ }^{31,34}$. Na obtenção de pus franca na toraconcentese diagnóstica, deve-se proceder à TC para esclarecimento dos fatores acima mencionados, em razão de sua alta prevalência nesses casos, evitando-se assim a inserção desnecessária do dreno ${ }^{34}$.

Apesar de resultados favoráveis com uso de fibrinolíticos observados tanto em séries retrospectivas ${ }^{38-40}$ como em estudos controlados ${ }^{42-47}$, seu uso ainda é polêmico. Em teoria, estaria indicado classicamente para casos da categoria 3 da ACCP, resistentes à TDF pela presença de loculações, mas ainda poderia ser aconselhado em casos de categoria 4 na ausência de espessamento pleural. Não obstante a meta-análise de Colice et al. ${ }^{15}$ ter confirmado tal superioridade (mortalidade média de 4,3\%; 95\% IC: $1,2-10,5 \%$ e taxa de sucesso de $85,1 \%$; $95 \%$ IC: $76,3-$ $91,6 \%)$, este trabalho foi realizado antes do estudo MIST- $1^{19}$, o de desenho mais adequado e de maior casuística, que negou tais resultados. De fato, metaanálises ${ }^{70,71}$ realizadas posteriormente não mostraram diferenças entre o uso de fibrinolíticos e placebo. Sendo assim, até que estudos analisando o efeito da adição de DNAase sejam realizados, sua utilização rotineira não é recomendada e deve se restringir a casos específicos, como aqueles resistentes à DPP, mas que por condições clínicas ou técnicas locais, o emprego de abordagem cirúrgica não pode ser efetuado.

No tocante à decorticação cirúrgica, notase pelos estudos existentes na literatura que consiste em um método de uso bem estabelecido e com indicações precisas: manutenção do quadro mesmo após implementação de TDF e existência de multiloculações ou espessamento pleural. $\mathrm{Na}$ meta-análise de Colice et al. ${ }^{15}$, observam-se uma taxa de sucesso de $89,3 \%$ (95\% IC: $85,4-95,7 \%$ ) e um índice de mortalidade de 1,9\% (95\% IC: $0,9-16,2 \%)$ para o procedimento aberto. Está estabelecido que a eficiência da VATS é semelhante à da toracotomia quando apenas a deloculação e limpeza da cavidade são necessárias (casos de fase II), com a vantagem de ser um procedimento minimamente invasivo, acarretando menor tempo de permanência de dreno ${ }^{54,63,65,75}$, alta hospitalar mais precoce ${ }^{54,58,63,64,66,75-78}$ e maior conforto ao paciente ${ }^{64,76}$. Para casos de fase III, é provável que a experiência da equipe cirúrgica atue como um fator decisivo para a resolução do quadro. Embora não existam estudos controlados randomizados abordando 0 assunto, as séries mostram uma taxa de sucesso considerável ( 54 a 82, $8 \%{ }^{52,53,58,59,62,66,76-78}$ ) com o uso de VATS, de modo que se recomenda sua utilização mesmo nesses casos, visto que a conversão para toracotomia pode ser facilmente realizada no intraoperatório caso a remoção do espessamento pleural seja deficiente e comprometa a expansão pulmonar. Contudo, deve-se ressaltar que o prolongamento 
Waisberg et al. Conduta cirúrgica do derrame pleural parapneumônico em adultos.

do tempo entre o diagnóstico e a intervenção cirúrgica está associado à maior índice de conversão para toracotomia ${ }^{34,58,60,63,65-66}$ e, mesmo para casos inicialmente referidos para o procedimento aberto, tal situação eleva a morbimortalidade ${ }^{23,24,67-69}$ e o custo ${ }^{31}$ da operação, como se verifica no tempo de internação maior nos casos submetidos à TDF comparados àqueles que o foram à toracotomia ${ }^{23,24,31}$.

Propusemos então um algoritmo de conduta terapêutica baseado nos resultados mostrados na literatura para método de tratamento do DPP (Figura 1).

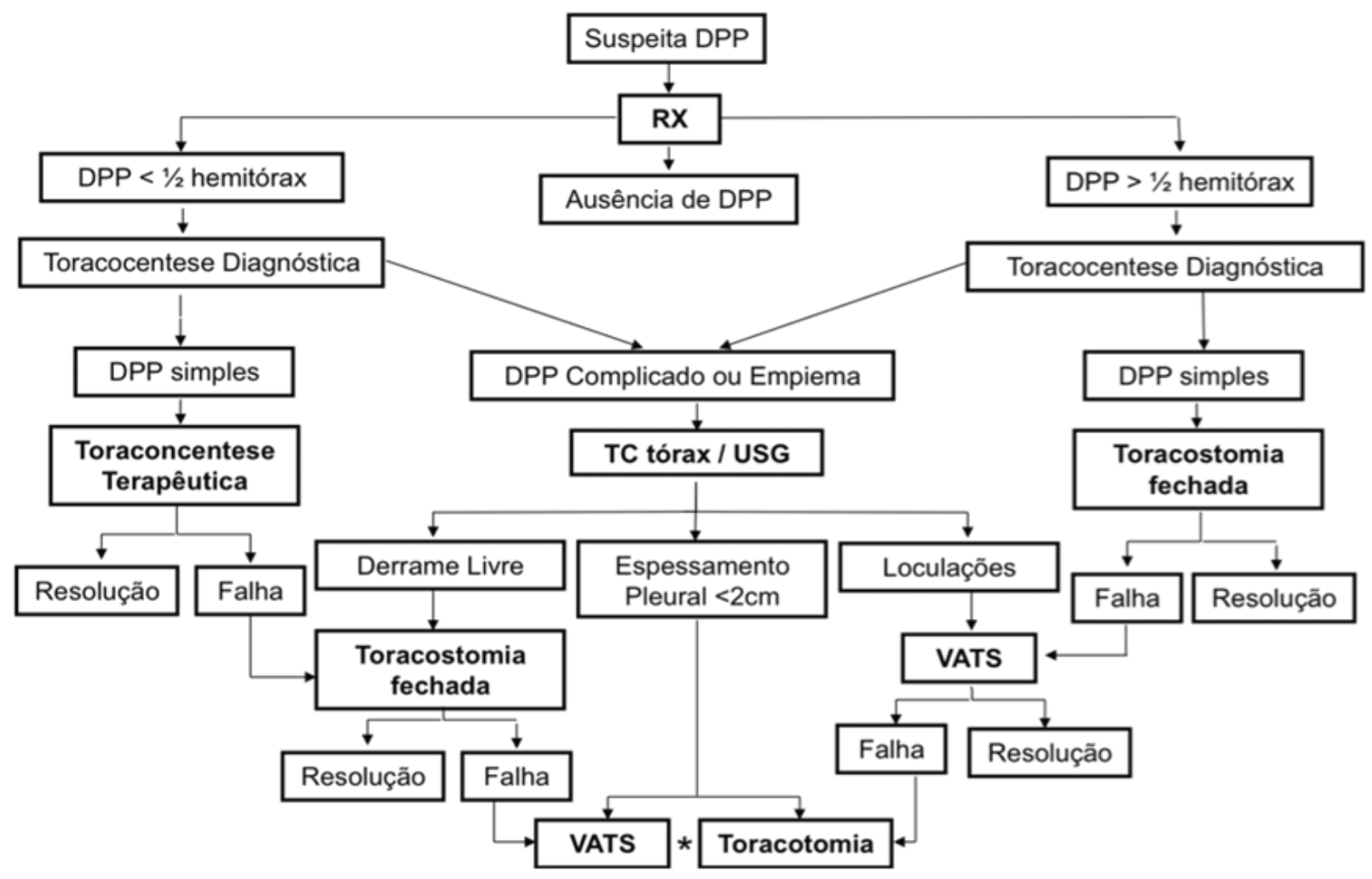

FIGURA 1. Algoritmo de conduta para o Derrame Pleural Parapneumônico (DPP). RX: radiografia de tórax póstero-lateral, TC: tomografia computadorizada de tórax, USG: ultra-som torácico, VATS: Vídeo-assisted Thoracoscopic Surgery*: em casos de espessamento pleural, o uso de VATS ou toracotomia depende da preferência do cirurgião, embora o uso da primeira seja recomendado pela eficácia semelhante, caráter minimamente invasivo e facilidade de conversão no intra-operatório

\section{REFERÊNCIAS}

1. Light RW. Pleural diseases. 4th ed. Baltimore: Lippincott Williams and Wilkins; 2001.

2. Molnar TF. Current surgical treatment of thoracic empyema in adults. Eur J CardioThorac Surg. 2007;32:422-30.

3. Koegelenberg CF, Diacon AH, Bollinger CT. Parapneumonic pleural effusion and empyema. Respiration. 2008;75:241-50.

4. Cameron RJ. Management of complicated parapneumonic effusions and thoracic empyema. Int Med J. 2002;32:408-11.

5. Light RW. Parapneumonic effusions and empyema. Proc Am Thorac Soc. 2006;3:75-80.

6. Hasley PB, Albaum MN, Li YH, Fuhrman CR, Britton CA, Marrie TJ, Singer DE, Coley CM, Kapoor WN, Fine MJ. Do pulmonary radiographic findings at presentation predict mortality in patients with community-acquired pneumonia? Arch Intern Med. 1996;156:2206-12
7. Rahman NM, Chapman SJ, Davies RJ. The approach to the patient with a parapneumonic effusion. Clin Chest Med. 2006;27:253-66.

8. Molnar TF, Hasse J, Jeyasingham K, Rendeki MS. Changing dogmas: history of development in treatment modalities of traumatic pneumothorax, hemothorax and posttraumnatic empyema thoracis. Ann Thorac Surg. 2004;77:372-8.

9. Vargas FS, Teixeira LR, Marchi E. Derrame pleural. São Paulo: Roca; 2004.

10. Light RW, MacGregor MI, Ball WC Jr, Luchsinger PC. Diagnostic significance of pleural fluid $\mathrm{pH}$ and PCO2. Chest. 1973;64:591-6.

11. Potts DE, Levin DC, Sahn SA. Pleural fluid $\mathrm{pH}$ in parapneumonic effusions. Chest. 1976;70:328-31.

12. Davies CW, Gleeson FV, Davies RJ. BTS guidelines for the management of pleural infection. Thorax. 2003;58(Suppl 2):ii18-28. 
13. Light RW. A New classification of parapneumonic effusions and empyema. Chest. 1995;108:299-301.

14. Heffner JE, Brown LK, Barbieri C, DeLeo JM. Pleural fluid chemical analysis in parapneumonic effusions. A meta-analysis. Am J Respir Crit Care Med. 1995;151:1700-8.

15. Colice GL, Curtis A, Deslauriers J, Heffner J, Light R, Littenberg B, Sahn S, Weinstein RA, Yusen RD. Medical and surgical treatment of parapneumonic effusions: an evidence-based guideline. Chest. 2000;118:1158-71.

16. Evans Al, Gleeson FV. Radiology in pleural disease: state of the art. Respirology. 2004;9:300-12.

17. Maskell NA, Davies CW, Nunn AJ. UK controlled trial of intrapleural streptokinase for pleural infection. N Engl J Med. 2005;352:865-74.

18. Civen R, Jousimies-Somer H, Marina M, Borenstein L, Shah $\mathrm{H}$, Finegold SM. A retrospective review of cases of anaerobic empyema and update of bacteriology. Clin Infect Dis. 1995;20:224-9.

19. Maskell NA, Davies CW, Nunn AJ. UK controlled trial of intrapleural streptokinase for pleural infection. N Engl J Med. 2005;352:865-74.

20. Fortes PA, Pommer VM, Cardoso AC, Marques ER. Aspectos clínicos e bacteriológicos do empiema pleural em crianças. Pediatria (S. Paulo). 1984;7:80-3.

21. Chapman SJ, Davies RJ. The management of pleural space infections. Respirology. 2004;9:4-11.

22. Colt HG, Brewer N, Barbur E. Evaluation of patient and procedure-related factors contributing to pneumothorax following thoracentesis. Chest. 1999;116:134-38.

23. Ferguson AD, Prescott RJ, Selkon JB, Watson D, Swiburn CR. The clinical course and management of thoracic empyema. Q J Medicine. 1996;89:285-89.

24. Mandal AK, Thadepalli H, Chettipally U. Outcome of primary empyema thoracis: therapeutic and microbiologic aspects. Ann Thorac Surg. 1998;66:17826.

25. Ozol D, Oktem S, Erdinc E. Complicated parapneumonic effusion and empyema thoracis: microbiologic and therapeutic aspects. Respir Med. 2006;100:286-91.

26. Simmers TA, Jie C, Sie B. Minimally invasive treatment of thoracic empyema. J Thorac Cardiovasc Surg. 1999;47:77-81.

27. Mandal AK, Thadepalli H. Treatment of spontaneous bacterial empyema thoracis. J Thorac Cardiovasc Surg. 1987; $94: 414-8$.

28. Lemmer JH, Botham MJ, Orringer MB. Modern management of adult thoracic empyema. J Thorac Cardiovasc Surg 1985;90:849-55

29. Storm HK, Krasnik M, Bang K, Frimodt-Møller N. Treatment pf pleural empyema secondary to pneumonia:thoracentesis regimen versus tube drainage. Thorax. 1992;47:821-4.

30. Sasse S, Nguyen T, Teixeira LR, Light RW. The utility of daily therapeutic thoracentesis for the treatment of early empyema. Chest. 1999;116:1703-8.

31. Thourani VH, Brady KM, Mansour KA, Miller JI, Lee RB. Evaluation of treatment modalities for thoracic empyema: a cost-effectiveness analysis. Ann Thorac Surg. 1998;66:1121-7.
32. Ulmer JL, Choplin RH, Reed JC. Image-guided catheter drainage of the infected pleural space. J Thorac Imaging. 1991;6:65-73.

33. Boland GW, Lee MJ, Silverman S, Mueller PR. Interventional radiology of the pleural space. Clin Radiol. 1995;50:205-14.

34. Lardinois D, Gock M, Pezetta E, Buchli C, Rousson V, Furrer M, Ris HB. Delayed referral and gram-negative organisms increase the conversion thoracotomy rate in patients undergoing video-assisted thoracoscopic surgery for empyema. Ann Thorac Surg. 2005;79:18516.

35. Huang HC, Chang HY, Chen CW, Lee CH, Hsiue TR. Predicting factors for outcome of tube thoracostomy in complicated parapneumonic effusions or empyema. Chest. 1999;115:751-6.

36. Tillet WS, Sheery S, Read CT. The use of strepkinasestrepdornase in the treatment of postpneumonic empyema. J Thorac Surg. 1951; 21: 275-297

37. Light RW, Nguyen T, Mulligan ME, Sasse SA. The in vitro efficacy of varidase versus streptokinase or urokinase for liquefying thick loculated empyema. Lung. 2000;178:13-8.

38. Bergh NP, Ekroth R, Larsson S, Nagy P. Intrapleural streptokinase in the treatment of haemothorax and empyema. Scand J Thorac Cardiovasc Surg. 1977;11:265-8.

39. Moulton JS, Benkert RE, Weisiger KH, Chambers JA Treatment of complicated pleural fluid collections with image-guided drainage and intracavitary urokinase. Chest. 1995;180:1252-9.

40. Temes RT, Follis F, Kessler RM, Pett SB Jr, Wernly JA. Intrapleural fibrinolytics in management of empyema thoracis. Chest. 1996;110:102-6.

41. Bouros D, Schiza S, Patsourakis G, Chalkiadakis G Panagou $P$, Siafakas NM. Intrapleural streptokinase versus urokinase in the treatment of complicated parapneumonic effusions: a prospective, double-blind study. Am J Respir Crit Care Med.. 1997;155:291-5.

42. Chin NK, Lim TK. Controlled trial of intrapleural streptokinase in the treatment of pleural empyema and complicated parapneumonic effusions. Chest. 1997;111:275-9.

43. Davies RJ, Trail ZC, Gleeson FV. Randomised controlled trial of intrapleural streptokinase in community acquired pleural infection. Thorax. 1997;52:416-21.

44. Bouros D, Schiza S, Tzanakis N, Chalkiadakis G, Drositis J, Siafakas N. Intrapleural urokinase versus normal saline in the treatment of complicated parapneumonic effusions and empyema. Am J Respir Crit Med. 1999;159:37-42.

45. Tuncozgur B, Ustunsoy H, Sivirkoz MC, Dikensoy O, Topal M, Sanli M, Elbeyli L. Intrapleural urokinase in the management of parapneumonic empyema: a randomized controlled trial. Int $\mathrm{J}$ Clin Pract. 2001;55:658-60.

46. Diacon $A H$, Theron Jm Schuurmans MM, Van De Wall BW, Bollinger CT. Intrapleural streptokinase for empyema and complicated parapneumonic effusions. Am J Respir Crit Care Med. 2004;170:49-53.

47. Misthos P, Sepsas E, Konstantinou M, Athanassiad 
K, Skottis I, Lioulias A. Early use of intrapleural fibrinolytics in the management of postpneumonic empyema. A prospective study. Eur J Cardiothorac Surg. 2005;28:599-603.

48. Simpson G, Roomes D, Heron M. Effects of streptokinase and deoxyribonuclease on viscosity of human surgical and empyema pus. Chest. 2000;117:1728-33.

49. Simpson G, Roomes D, Reeves B. Successful treatment of empyema thoracis with human recombinant deoxyribonuclease. Thorax. 2003;58:365-6.

50. Mayo P. Early thoracotomy and decortication for non-tuberculous empyema in adults with and without underlying deceases. A 25-year review. Am Surg. 1985;51:230-6.

51. Landreneau RJ, Keenan RJ, Hazelrigg SR, Mack MJ, Naunheim KS. Thoracoscopy for empyema and hemothorax. Chest. 1996;109:18-24

52. Ridley PD, Braimbridge MV. Thoracoscopic debridement and pleural irrigation in the management of empyema thoracis. Ann Thorac Surg. 1991;51:461-4.

53. Landreneau RJ, Keenan RJ, Hazelrigg SR, Mack MJ, Naunheim KS. Thoracoscopy for empyema and hemothorax. Chest. 1996;109:18-24.

54. Lawrence DR, Ohri SK, Moxon RE, Townsend ER, Fountain SW. Thoracoscopic debridement of empyema thoracis. Ann Thorac Surg. 1997;64:1448-50.

55. Striffeler H, Gugger M, Hof VI, Cerny A, Furrer M, Ris HB. Video-assisted thoracoscopic surgery for fibrinopurulent pleural empyema in 67 patients. Ann Thorac Surg. 1998;65:319-23.

56. Wurnig PN, Wittmer V, Pridun NS, Hollaus PH. Videoassisted thoracic surgery for pleural empyema. Ann Thorac Surg. 2006;81:309-13

57. Kim BY, Oh BS, Jang WC, Min Y, Park YK, Park JC. Video-assisted thoracoscopic decortication for management of postpneumonic pleural empyema. Am J Surg. 2004;118:321-4.

58. Luh SP, Chou MC, Wang LS, Chen JY, Tsai TP. Videoassisted thoracoscopic surgery in the treatment of complicated parapneumonic effusions or empyemas: outcome of 234 patients. Chest. 2005;127:1427-32.

59. Solaini L, Prusciano F, Bagioni P. Video-assisted thoracic surgery in the treatment of pleural empyema. Surg Endosc. 2007;21:280-4.

60. Roberts JR. Minimally invasive surgery in the treatment of empyema: intraoperative decision making. Ann Thorac Surg. 2003;76:225-30.

61. Cuniffe MG, Maguire D, McAnena OJ, Johnston S, Gilmartin JJ. Video-assisted thoracoscopic surgery in the management of loculated empyema. Surg Endosc. 2000;14:175-8.

62. Lackner RP, Hughes R, Anderson LA, Sammut PH, Thompson AB. Video-assisted evacuation of empyema is the preferred procedure for management of pleural space infections. Am J Surg. 2000;179:27-30.

63. Mackinlay TA, Lyons GA, Chimondeguy DJ, Piedras MA, Angaramo G, Emery J. VATS debridement versus thoracotomy in the treatment of loculated postpneumonia empyema. Ann Thorac Surg. 1996;61:1626-30.

64. Chan DT, Sihoe AD, Chan S, Tsang DS, Fang B,
Lee TW, Cheng LC. Surgical treatment for empyema thoracis: is video-assisted thoracic surgery "better" than thoracotomy? Ann Thorac Surg. 2007;84:225-31.

65. Podbielski FJ, Maniar HS, Rodriguez HE, Hernan MJ, Vigneswaran WT. Surgical strategy of complex empyema thoracis. JSLS. 2000;4:287-90.

66. Waller DA, Rengarajan A. Thoracoscopic decortication: a role for video-assisted surgery in chronic postpneumonic pleural empyema. Ann Thorac Surg. 2001;71:1813-6.

67. Bilgin M, Akcali Y, Oguzkaya F. Benefits of early aggressive management of empyema thoracis. ANZ J Surg. 2001;76:120-2.

68. Wait MA, Sharma S, Hon J, Nograe AD. A randomized trial of empyema therapy. Chest. 1997; 111:1548-51.

69. Petrakis IE, Kogerakis NE, Drositis IE, LAsithiotakis KG, Bouros D, Chialkiadakis GE. Video-assisted thoracoscopic surgery for thoracic empyema: primarily, or after fibrinolytic therapy failure? Am J Surg. 2004;187:471-4.

70. Bouros D, Antoniou KM, Chalkiadakis G, Drositis J, Petrakis I, Siafakas N. The role of video-assisted thoracoscopic surgey in the treatment of parapneumonic empyema after the failure of fibrinolytics. Surg Endosc. 2002;16:151-4.

71. Melloni G, Caretta A, Ciriaco P, Negri G, Voci C, Augello G, Zaninni P. Decortication for chronic parapneumonic empyema: results of a prospective study. World J Surg. 2004;28:488-93.

72. Pothula V, Krellenstein DJ. Early aggressive surgical management of parapneumonic empyemas. Chest. 1994;105:832-6.

73. Tokuda Y, Matsushima D, Stein GH, Miyagi S. Intrapleural fibrinolytic agents for empyema and complicated parapneumonic effusions: a meta-analysis. Chest. 2006; 129:783-90.

74. Cameron R, Davies HR. Intra-pleural fibrinolytic therapy versus conservative management in the treatment of adult parapneumonic effusions and empyema. Cochrane Database Syst Rev. 2008;16:CD002312.

75. Cardillo G, Carleo F, Carbone L, Martino MD, Salvadori L, Petrella L, Martelli M. Chronic postpneumonic pleural empyema: comparative merits of thoracoscopic versus open decortication. Eur J Cardiothorac Surg. 2009;36:914-8.

76. Casali C, Storelli ES, Prima ED, Morandi U. Longterm functional results after surgical treatment of parapneumonic thoracic empyema. Interact Cardiovasc Thorac Surg. 2009;9:74-8.

77. Shahin Y, Duffy J, Beggs D, Black E, Majewski A. Surgical management of primary empyema of the pleural cavity: outcome of 81 patients. Interact Cardiovasc Thorac Surg 2010;10:565-7.

78. Tong BC, Hanna J, Toloza EM, Onaitis MW, D'Amico TA, Harpole DH, Burfeind WR. Outcomes of videoassisted thoracoscopic decortication. Ann Thorac Surg. 2010;89:220-5.

Artigo premiado COMU: 18-23/10/10. 